\title{
THREE LIES OF DIGITAL ETHNOGRAPHY
}

\author{
Gabriele de Seta*
}

\begin{abstract}
The relative novelty of digital ethnography as a research methodology, along with the challenges that it moves to classical understandings of fieldwork, participation and representation, results in a repertoire of professional illusions through which digital ethnographers justify their work when confronted with the disciplinary culture of anthropology. This essay is based on the author's reflexive experience of researching digital media use in China, and updates Gary Alan Fine's 1993 article "Ten Lies of Ethnography" by identifying three lies of digital ethnography. Illustrating each of these lies through an archetypal figure - the 'networked field-weaver', the 'eager participant-lurker' and the 'expert fabricator' - this article argues for the need to confront methodological illusions and embrace the tensions behind them as useful heuristics for conducting ethnographic research on, through and about digital media.
\end{abstract}

Keywords: digital ethnography; disciplinary culture; epistemic community; ethics; fabrication; fieldwork; lying; participation; self-reflexivity

${ }^{*}$ University of Bergen, Norway. 


\section{ELEVATOR PITCH}

Here is my elevator pitch, a professional mantra I have been practicing during my two years as a postdoctoral researcher at each new encounter with a fellow academic:

What do I do? I am a media anthropologist, I study digital media use in China. Yes, mostly urban areas, young people... I focus on creative practices. I've written about several things, from independent music and contemporary art to selfies and dating apps... no, I don't just go on the internet, I do on-site fieldwork. Where? Mostly in Shanghai, but my doctoral fieldwork included eight cities in total, it was a multi-sited project, yeah. How long was my fieldwork? The 'actual' one was six months, but I've been doing online ethnography for a whole year before that, so... oh, fifth floor, I get down here. Bye, bye.

I usually exhale a deep breath after each time I recite my elevator pitch. I am honing it, I am getting better, and the better it gets, the less truthful it feels. The more the weeks of traveling between cities on night trains, sleeping in hostels and friends' houses and transcribing social media interactions recede back in the past, the more I realise that the assemblage of disciplinary imperatives, epistemological nudges and promises of legitimation I integrated into my research project keep determining how I carefully massage its description according to the needs of the moment. This is not to imply that my fieldwork was an elaborate act of fakery, nor that it is now time for me to come clean about some sort of methodological cheating - it is just that my elevator pitch remains an intimately distasteful performance. But why?

I realise that most of the times I describe my research project to colleagues I end up performing a gentle choreography of professionalism and persuasion - I avoid talking about the challenging aspects of my research or my actual methodological practices, and instead carefully piece together a string of keywords and abstracted data points meant to prove my disciplinary belonging. One of the things I tend to do is emphasising the anthropological nature of my fieldwork in order to preventively justify my own self-labelling as a media anthropologist (I have a $\mathrm{PhD}$ in Sociology, which makes of me a suspect disciplinary outsider). Another choreographic figuration is the stretching of my fieldwork period to one year and its subdivision into two segments - one 'online' and one 'offline' - through which I manage to avoid the doubtful remarks of anthropologists who evaluate my work against the golden minimum of a year spent in a bounded locale, while also responding to the occasional insinuations of methodological laziness: 'Internet fieldwork... you're so lucky, you can just sit at home and browse Facebook, right?'. A third rhetorical strategy is offering a few examples of popular topics I have written about to cover up the apparent lack of a central research focus: unfortunately, digital media practices are not yet a staple domain of anthropological inquiry like religion, kinship or performance, and claiming that I do ethnographic research about emoji, selfies or trolling often drives the point home well enough, if with some lingering puzzlement. 
The tensions motivating my resort to these half-truths, strategic simplifications and circumstantial lies are nothing new: like many other academic domains, anthropology has its own disciplinary cultures, and methodology is perhaps the level at which these are most evident. As the central rite of passage for anthropologists, ethnographic fieldwork remains a marker of authority (Hastrup 1990, p. 43) and an experiential focus for the construction of professional identity (Moser 2007, p. 243). We measure our epistemological decisions and methodological descriptions against prescriptions on what is (or is not) 'ethnographic', on how long or focused a period of research should be in order to qualify as 'fieldwork', on what counts as 'data', and so on. We are also tempted to deploy these choices as tepidly confrontational probes among colleagues: as with any other methodological approach, staking claims about one's own ethnographic experience is a central routine of scholarly performances of community, and doing a hatchet job of one's actual research process becomes part and parcel of the collegial negotiations of professional identity and standards of competence (Hine 2005, p. 8).

The relative novelty of certain research topics in any disciplinary domain (in my case, communication technologies in anthropology) makes them more prone to generalisations and requires simplifying the presentation of one's work. The grass seems always greener on the neighbour's disciplinary turf, and twenty years after the earliest calls for 'anthropologies of the Internet' (Ito 1996; Nardi 1996) I still find myself in need to counter the assumption that studying digital media is 'so fashionable now' or 'very easy to find a job with', often paired with attempts at signposting my research under other disciplines such as media or cultural studies. Despite the wealth of methodological discussions of the topic (Baym \& Markham 2009; Hine 2000; Pink et al. 2016), approaching digital media from an ethnographic perspective remains something seemingly in particular need of excuses and apologetic remarks (Hine 2013, p. 28).

\section{THREE LIES OF DIGITAL ETHNOGRAPHY}

In navigating disciplinary contexts fraught with performative gatekeeping and methodological tensions, which lies do we digital ethnographers most often tell ourselves and others? My question isn't novel - as a matter of fact, this entire essay is the consequence of revisiting Gary Alan Fine's Ten Lies of Ethnography (1993), an academic article that I found extremely liberating while I was preparing my own doctoral research proposal. In this widely quoted piece, Fine skirts the fascination for laying bare the uncomfortable truths of the trade and instead focuses on the unavoidable instances of lying that accompany much ethnographic research. ${ }^{1}$ According to the author, illusions about ethnography, regularly hidden in its methodological backstage, are necessary for both the production of good work and occupational survival, but become problematic when they take root and become taken for real by its practitioners (Fine 1993, pp. 267-268). Fine decides to use the 
loaded word 'lies' to indicate the illusions that result from the choices made by ethnographers responding to their work conditions, textual forms of output, and requirements of secrecy (p. 269), and identifies the titular 'ten lies of ethnography' hidden behind archetypal professional figures such as the friendly ethnographer, the precise ethnographer, the unobtrusive ethnographer, the chaste ethnographer, the literary ethnographer, and so on.

In a later essay, Fine and Shulman revisit these ten lies in the context of organisational ethnography (2009), observing how the relatively new methodological approach is also prone to similar forms of sanitisation and makebelieve: ethnographers doing organisational research might tend to obfuscate the details about their information-gathering, skirt the practicalities of ethical dilemmas (p. 177), stash away fieldnotes and data analysis in an inaccessible backstage, accept secrecy for granted (p. 178) and hide the way access is sometimes obtained through acquaintances, friends or even family connections (p. 179). It would be quite straightforward to rephrase these epistemological warnings for ethnographic approaches to digital media, and in fact years of methodological discussions have already covered these grounds. For example, according to Anne Beaulieu's review of methodological literature, researchers tend to articulate the peculiarity of digital ethnography through four 'strategies of objectification' responding to specific tensions: the fuzziness of the field, the agency of technology, the reliance on intersubjectivity and the allure of capture (2004, p. 146). In the following sections of this article, I put forward three lies of digital ethnography. The three archetypal figures of digital ethnographers I describe are stylistically inspired by Fine's pantheon of disciplinary illusions and include obvious overlaps with long-standing methodological conundrums, but are also distinctive in how they personify, combine and question Beaulieu's four strategies of objectification.

In writing this article, I am not in search of scandalous unveilings, and my goal is decidedly not telling ugly or cynical truths in the (ideally) public space of an academic journal, nor accusing others of engaging in dishonesty and deception. Instead, the three illusive figures that follow embody discursive strategies, performative masks, and illusory identities that I regularly confront in my thinking, speaking, and writing about my own research work. The hope is that both colleagues approaching the disciplinary domain of digital ethnography as well as fellow researchers already familiar with this methodological assemblage can recognise their own doubts and concerns in some of these portraits. This is not an essay that tells you how to 'do' digital ethnography, but rather one confessing some of the lies that necessarily accompany the practice. In the following sections, I discuss three lies of digital ethnography through three archetypal figures: the 'networked field-weaver', the 'eager participant-lurker' and the 'expert fabricator.' 


\section{THE NETWORKED FIELD-WEAVER}

The first lie of digital ethnography is related to one of the most widely debated ethnographic constructs: the 'field'. Questioned, fragmented and deconstructed in much anthropological scholarship in the wake of the writing culture debates (Clifford \& Marcus 1986), the field remains an anchor for debates around the practice of research (Amit 2000), and functions as one of the main concepts around which digital ethnographers expound the peculiarities of their methodology (Beaulieu 2004, p. 144). Undeniably, the proposal for a 'multi-sited ethnography' outlined by George E. Marcus has become a foundational text for researchers seeking to articulate ways of doing fieldwork outside of the limitations and biases inherent in bounded fieldsites. In order to move across multiple sites, the ethnographer has at her disposal techniques to follow and trace people, things, metaphors, narratives, biographies, conflicts, and so on (Marcus 1995, p. 105). After Marcus's proposal, authors writing about the ethnographic field in the context of new technologies have expanded and refined his ideas by arguing for trans-local (Ito 1996), multimodal (Dicks et al. 2006), or connective (Hine 2007) ethnography (among many other similar formulations). And yet, in spite of wide-ranging debates regarding the new possibilities offered by multi-local, multi-sited or multi-modal fieldwork, the prescriptive model outlined by Evans-Pritchard and based on the "both celebrated and mystified notion of "being there"'(Hannerz 2003, p. 202) has

for very long remained more or less the only fully publicly acknowledged model for field work, and for becoming and being a real anthropologist. Perhaps it works with full force especially in the continued instruction of newcomers in the discipline. (p. 202)

As a disciplinary outsider, I experienced first-hand the force of this idea when I started putting together the methodological section of my doctoral research proposal: eager to push back against a large body of existing research on Chinese digital media that was largely based on quantitative studies and cursory engagement with online phenomena, I embraced the promising ethnographic tenet of 'being there' and elected it as the central research strategy guiding my epistemological choices. Throughout my fieldwork experience, 'being there' became not only a matter of immersing myself in a local context and going phenomenologically native (Hastrup 1990, p. 46), but an actual, pragmatic sociotechnical condition that my informants continuously inquired about each other - and even sometimes demanded of me - across the communication channels offered by multiple digital media platforms. From QQ group chatrooms to private messages on Sina Weibo, and from Facebook messaging windows to smartphone conversations on WeChat, the Mandarin Chinese salutation zai ma? [Are you here?] was used as a way to initiate interaction by checking for my digital presence and communicative availability (Fig. 1). In this sense, Hannerz's summation of multi-sited fieldwork as 'being there ... and there ... and there' (Hannerz 2003, p. 202) provided a useful 
model for articulating my ideal fieldwork attitude as being online, being visible, being available, being interacting, and so on. In my own words,

[...] 'being there', on different platforms and services, different conversations and groups, updated and in-the-loop regarding different topics and events: the spatial experience of the Internet was way more social than technological. (de Seta 2015, pp. 41-42)

The multiple possibilities of 'being there' in different locales, digital media platforms and social settings resonated with the pleas for a combination of online and real-life contexts repeatedly made ever since the earliest proposals for anthropological approaches to the internet (Ito 1996, p. 25). Moreover, embracing different ways of 'being there' dovetailed with depictions of an increasingly connective ethnography requiring the researcher to 'choose a perceived community and select the important nodes in the social network as field sites' (Howard 2002, p. 561).

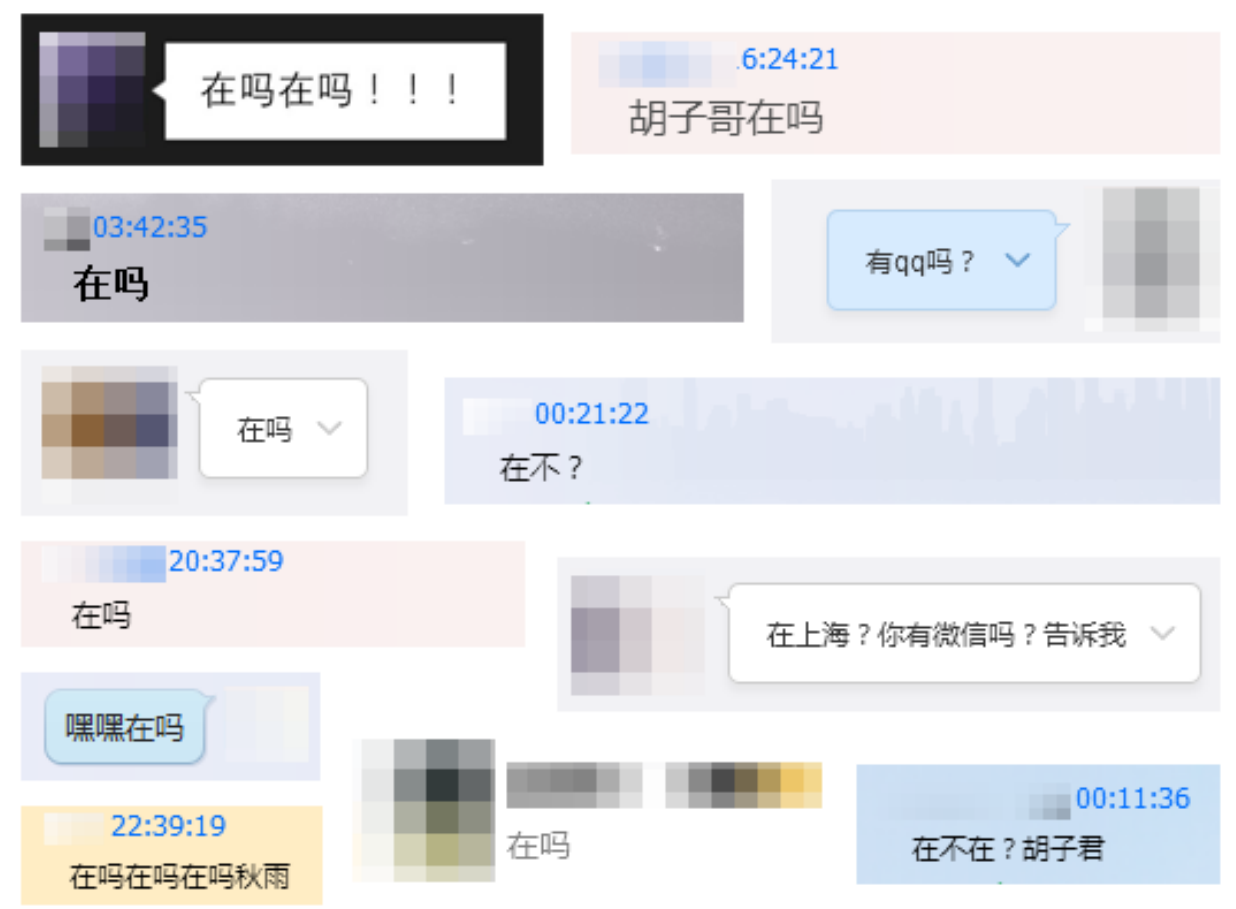

Figure 1: 'Being there' as a way of establishing co-presence on digital media: 'Are you here? Are you here?', 'Brother Beard are you here?', 'Are you here?', 'Do you have QQ?', 'Here or not?', 'Are you in Shanghai? Do you have WeChat? Tell me', 'Hey-hey are you here?', 'Areyouhereareyouhere?', 'Mr. Beard are you here or not?'. Collage of cropped screenshots by the author, 2015.

When I embarked on my fieldwork, the most convincing metaphor I had come across was the one provided by Jenna Burrell in her famous proposition of 'the field site as a network' (2009). Building upon Marcus's and Hannerz's idea of multi-sited 
ethnography, Burrell emphasises how it is the ethnographer herself, through the everyday tracing of different actors, that pulls together the field as a network (2009, p. 187). Over the years, I have found myself comfortably adopting Burrell's insight: my own 'field as network' included a group of friends and acquaintances, longer and shorter stays in eight Chinese cities, a number of online platforms, an inventory of mobile devices, a sample of linguistic repertoires, certain genres of online content, mass media discourses about the internet, and a variety of media practices. By weaving together an observation made in a student housing in Wuhan, a heartfelt WeChat discussion with a Beijing friend conducted while walking on the streets of Hong Kong, a QQ group conversation with people I had never met, and an interview with a Shanghainese office lady in a fancy cafe, I was able to offer a variegated portrait of how people used digital media in China. As a field, this assemblage pulled together the situated occurrences and happenstance moments I cherry-picked out of a hundred of fieldnotes about everyday life encounters; as a network, it remained productively open-ended, and could be interfaced with larger analytical constructions such as 'contemporary China' or 'the internet', while also functioning as an explanatory backdrop for smaller questions regarding individual case studies or specific data points.

As with many solutions that seem to work all too well, I started realising that my idealised reliance on weaving fields as networks was built on lying about something. The enticing lie of the networked field-weaver is that, rather than experiencing the expansive movement of branching out promised by this metaphor, I often found myself building my 'field as network' by grasping at straws, and immediately cutting away most of what came along with them. The problem of cutting networks that would otherwise proliferate uncontrollably already troubled anthropologists working in bounded fieldsites (Strathern 1996), and it is obviously aggravated by the move from field to networks (Wittel 2000). A few months into my fieldwork, an interviewee sends me a link to a news article about a burgeoning online phenomenon, telling me 'You should write about this.' Should I really? How deep should I look into it? Will it fit my account? During my last stretch of research, a friend of a friend introduces me to a group of local comic book artists publishing their work on microblogging platforms: Should I interview some of them and deepen my understanding of their creative labour? Could I include some of their work in my dissertation? How should I treat their authorship? Attending a concert in a county town puts me in contact with some young urbanites reinventing their lives in the countryside tourist industry: Should I include their use of digital media use as a challenge to my research focus on urban areas? Should I pull this locale into my field as well? If yes, at what scale?

Weaving networks into an ethnographic field can bring the most disparate things together, and particularly when one's research topic is not extremely narrow, each node of the network can result in dizzying vertigos over a wealth of potential interlocutors, unexplored communities, or entirely new categories of data. Under the constraints of institutional time and limited funding, the answers to these 
recurring questions often imply cutting away outbranching connections, declining offers of furthering socialisation, and sealing off information outside the scope of a research project for the sake of its timely completion. So, besides the important acknowledgement of how these networked fields come together gradually and by chance (Hannerz 2003, p. 207), shaped by the ethnographer's reliance on the 'mechanical objectivity' of technological black boxes (Beaulieu 2004, p. 148), I find it necessary to problematise the idea of the 'field as network' by highlighting how it is unavoidably built on disconnection as much as connection. As Marilyn Strathern observed, the power of network models is also their weakness:

[...] one can always discover networks within networks; this is the fractal logic that renders any length a multiple of other lengths, or a link in a chain a chain of further links. Yet analysis, like interpretation, must have a point; it must be enacted as a stopping place. (1996 p. 523)

According to Strathern, one such mechanism for cutting networks is the EuroAmerican idea of ownership, which can simultaneously bound belonging and condense endless chains into an artefact, 'so where technology might enlarge networks, proprietorship can be guaranteed to cut them down to size' (p. 531). Academic writing is a similar mechanism: in order to decide what does or doesn't belongs in one's research project and to produce a viable written report, the ethnographer continuously prunes down networks as they proliferate, constructing a skeletal 'field as network' that eventually feels more like a crooked bonsai tree than an expanse of thick experiential wilderness. This network of fieldsites is rarely weaved in the same way twice: when writing journal articles, book chapters and shorter essays during and after my graduate studies, I realised that I would routinely pull back some of the same data into new configurations, expanding and reducing the 'field as network' according to both the discursive positioning of my research and on the rhetorical necessities of my imagined audience. In conclusion, while the idea of the field as network, like many other ' $\mathrm{x}$-as-network' metaphors, is a useful and productive heuristic to think of ethnographic fields 'as constellations of power relations and institutional entanglements, mediated through technologies' (Levy 2015), the lie of the ethnographer as networked field-weaver who 'alone oversees the multi-sites he chooses and he alone sees the patterns' (Farnsworth \& Austrin 2010, p. 1130) should be kept in mind, as it hides the cutting as much as it glorifies the pulling together.

\section{THE EAGER PARTICIPANT-LURKER}

The second lie of digital ethnography relates to the central practice of this research approach: participant observation. The issue of how participatory an anthropologist's observations should be is already hotly debated in more traditional research domains; yet, in the case of projects focusing on digital media platforms and media practices, defining standards of participation is even less straightforward. 
In my personal experience, the recurring question: 'what exactly did you do during your fieldwork?' becomes particularly awkward to answer, and often results in a jumbled mix of claims about using certain digital media platforms, collecting certain forms of online content, and spending time with a certain number of users in everyday situations. As a matter of fact, my 'doing ethnography' is grounded on several layers of involvement, and done through multiple forms of participation and observation. Given my extended periods of residence in China, I had been using a selection of local digital media platforms (from early discussion forums and instant messaging applications to newer social networking websites and microblogging services) since way before the beginning of my graduate program and the decision of my doctoral research topic; this personal history of everyday use constituted a baseline for getting a sense of the many possibilities of research. Once I narrowed down my proposal to a study of vernacular creativity on digital media (Burgess 2006), I started to pay more attention to certain platforms, user practices and genres of content, and then moved to expand specific lines of inquiry by finding more relevant online communities, exploring new platforms, making contact with potential informants, and so on.

While my initial research proposal mostly relied on my experiences of using social networking websites and microblogging services such as Douban and Sina Weibo, my doctoral proposal focused on increasingly popular messaging app WeChat, which most of my informants were adopting at the time. Once I was formally and physically 'on fieldwork', not much changed: I was still browsing websites, scrolling through social media feeds, chatting with friends, liking their posts, commenting on news stories, watching and listening to content shared by my contacts, collecting samples of interactions and writing fieldnotes to wrap up daily observations and encounters. The only thing that changed was that I wasn't sitting at my Hong Kong office desk, but rather wandering in Shenzhen, Wuhan, Shanghai, or Beijing, meeting friends I had not seen for a while, spending time with my partner, playing at experimental music concerts, and sitting in cafes with interviewees. Sure, I didn't have a $4 \mathrm{G}$ data plan on my mobile phone, and Facebook, Twitter, Google and YouTube weren't available, but I gladly embraced these 'Chinese characteristics' as part of the immersion in the much touted sociotechnical 'there' I was looking forward to experience. But how participatory was this experience?

The problematic status of participation in digital ethnography is directly linked to the design of digital media platforms. In spite of the commercial and cultural hypes around Web 2.0, participatory media and user-generated content (Jenkins et al. 2013), and even considering how many internet companies are largely sustained by amateur content creators, it is still the case that a large percentage of everyday interactions with websites, apps and online services are dominated by practices of reading, watching and querying that are not explicitly participatory. While participating in the social life of a district, a rural community or a nongovernmental organisation can seem easy to evaluate, recent debates on the role of 
participation in both classic and multi-sited ethnographies have laid bare the uncertain status of this 'particular kind of presence in the field' (Hastrup 1990, p. 49), which is often deployed to claim authorial expertise while flattening a variety of difficulties and boundaries that one inevitably encounters. Along with activities and events that are worth participating in, ethnographers come across many others that may be 'monotonous, isolated, and difficult to access' (Hannerz 2003, p. 211). Participation in digital media is similarly diffracted into a spectrum going from non-use to intensive and active presence, and extends in different dimensions according to the platforms used, the devices at hand, software availability, access to connectivity in time and space, as well as the social circles one participates in.

When confronted with this wide spectrum of possible modes of participation, digital ethnographers resort to different strategies to rethink their own research practices. In the earliest ethnographies of online settings, pioneering researchers emphasised the need to 'get the seats of our pants dirty' by trying to understand online communities through participatory involvement (Paccagnella 1997) and found in the figure of the 'lurker' a productive archetype embodying the contradictory status of participation on the internet. In her study of the Lesbian Cafe Bulletin Board System, Correll (1995) attributes ethnographic qualities to lurkers themselves, who are described as careful observers spending time without participating in the community in order to learn the appropriate codes before tentatively joining its activities (p. 293). Reflecting on this figure of participation, Leander \& McKim (2003) conclude that choosing between being an active participant or a lurker, a digital ethnographer makes important epistemological decisions. Given the increasing variety of modes of participation offered by digital media platforms, more recent debates have tried to move beyond a clear-cut choice between active participation and lurking, and instead to explore the creation of intersubjectivity as a fluid outcome of an ongoing ethnographic engagement (Beaulieu, 2004, p. 151), arguing for the need to triangulate different forms of participation in online and offline contexts (Orgad 2005, p. 51), extending the notion of participation to very personal activities like browsing, following links and moving between platforms (Hine 2007, p. 625), or complementing observations of online activities with spending time with users in their everyday life settings (Boyd 2008, p. 120).

What was once a folk figure of Bulletin Board Systems (BBSs) and MultiUser Dungeons (MUDs) is increasingly diffracted into a wide variety of modes of participation that users likely move through across time and space - in my own experience, managing their availability on QQ setting up automatic email replies, microblogging about their movements, checking in public or private places, joining group discussions on WeChat, shutting down their phones, and so on. Lurking becomes just a possibility alongside practices such as ignoring, reading, liking, commenting, sharing, editing, and linking, which are all modes of participation that can be adopted situationally across different platforms and identities, and that ethnographers are asked to understand and incorporate in their own work. In order 
to try to capture this diffraction of participatory modalities, Anne Beaulieu proposes a shift 'from co-location to co-presence' as a way to attune the ethnographer to different modes of interaction:

Not only does it enable the researcher to take mediated settings very seriously [...], but it also does not exclude face-to-face situations. Co-presence as a starting point enables a more symmetrical treatment of forms of interaction. (2010, p. 454)

Echoing this shift, Postill (2017) argues that digital media allow to successfully practice ethnography at a distance, since it becomes possible to participate immersively in a distant context and remain engaged with it without the necessity of co-location, anchoring short-term visits to interactions followed through online communications.

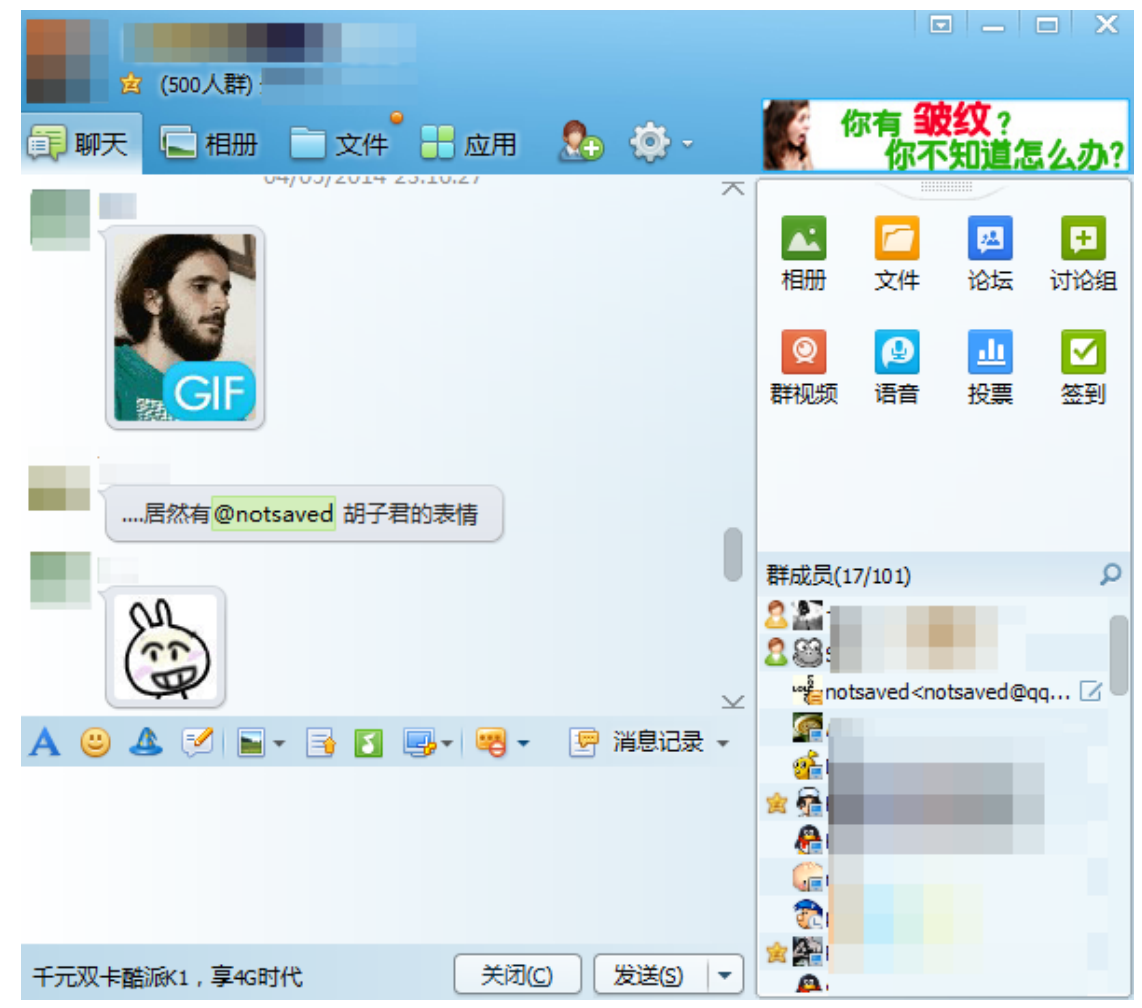

Figure 2: '...unexpectedly there is an emoticon of @notsaved buzi jun ['Mr. Beard', the author's Chinese nickname]' - a friend shares an animated. GIF image of myself with other members of the LightWave QQ group. Cropped screenshot by the author, April 2014.

Looking back at my own research experiences confirms this fluid nature of participation: for years, I have used Chinese digital media platforms as a way to keep in touch with local friends regardless of my physical location, to remain informed about local happenings around me, and to keep tabs on larger discussions around popular topics and newsworthy events; I've drifted in and out of social circles, discussion boards, microblogging platforms and private chatrooms, 
sometimes with the hidden or declared intent of collecting research data, other times for pragmatic purposes or just following the dynamic changes of my personal relationships. In some cases, I moved from lurking, to liking, to commenting, to discussing, to being present and back, according to circumstances, interest and availability. When I met with friends, acquaintances or strangers, I sometimes participated in interactions, sometimes withdrew from them. While 'on fieldwork', I recurrently mused about how being stuck with nothing to do for a day or more in a hotel room without a $\mathrm{Wi}-\mathrm{Fi}$ connection seemed in fact much less participatory than if I were in Hong Kong in front of my office computer. Yet, while recognising and reflecting on the nuances of these interlocking modes of participation, I still felt the need to condense them into simplified vignettes highlighting my presence and integration in a selection of social contexts: a photo of my face, transformed into animated GIF and used as sticker in a QQ chat group (Fig. 2), or my anonymous account, debating with other anonymous users on a discussion board, or my avatar and nicknames, the only non-blurred ones in a screenshot of a WeChat conversation.

Rather than reflecting on what different modes of participation meant for me and the people around me (whom I ironically still called 'participants'), I preferred focusing on answering the 'what did you exactly do during your fieldwork?' question in a professional manner, flattening my involvement into easily understandable nuggets of interaction proving my active presence in the field. Confronted by the injunctions of participant observation, I wrote myself into an eager participantlurker: a master of all modes of participation, portrayed as impossibly co-located across multiple fieldsites, surveying digital media use from a vantage of carefully crafted presence. Besides the false choice between naturalist lurking and active involvement, the issue of participation should become a central concern of digital ethnography instead of a purely methodological decision. We participate, just like our 'research participants', through a wide range of modes of participation tightly connected to social dynamics and technological affordances, that go from the choice of shutting down one's smartphone to the visceral need to sustain one's presence in a tense online discussion. Choices about these participatory modes punctuate our everyday engagement with digital media, and embracing the uncertainty (Hine 2013, p. 80) resulting from the way these situated decisions are negotiated and made sense of is probably of more interest than flattening one's own persona into the apologetic figure of an eager participant-lurker.

\section{THE EXPERT FABRICATOR}

The third lie of digital ethnography has to do with representation, which is an unavoidable component of producing any kind of research output. Digital ethnographers have the advantage of working with already highly mediated settings and are able to include in their reports samples of online resources, snippets of interactions, creative data visualisations, as well as image files, videos, and audio 
components. Whereas the ubiquity of communication technologies and the retrievability of mediated data has troubled the traditional anthropological model relying on face-to-face data collection and authorial transcription (Beaulieu 2004, p. 154), the recognition that 'the various "traces" that are left by users and uses of the technologies can be integrated into an ethnographic approach' (p. 145) has reoriented the research approaches of digital ethnographers towards new forms of data, methodological tools and multimedia representations (Dicks et al. 2006, p. 77). Anne Beaulieu identifies in these traces not only interpretable trails of user interaction but 'inscriptions', veritable 'modes of mediation' that digital ethnographers should not simply take notice of, but 'find a way to fully embrace them as part of the field' (2010, p. 457). Approaches such as trace ethnography (Geiger \& Ribes 2011) and digital methods (Rogers 2013) suggest practical ways of embracing these inscriptions, following the patterns their distribution outlines, and repurposing them into integral parts of one's account and findings.

In my own research work, I often try to complement written accounts with inscriptions ranging from samples of textual interactions to visual resources such as collages of image repertoires, screenshots of user interfaces, collections of stills from popular video content, and photographic documentations of digital media use in everyday contexts. I argue that these inscriptions help bridging the divide between academic writing and the multiple forms of communicative activities practiced on digital media, while also functioning as data points anchoring theoretical discussions. For example, by weaving a chat history transcript from a ten-people discussion on $\mathrm{QQ}_{2}$ a collage of the images and links shared during the conversation, and a screenshot of the software window into a descriptive analysis of group-based social media use, I not only provide readers with visual cues useful to imagine how the messaging software's user experience shapes and sustains the creation of linguistic and semiotic repertoires, but also incorporate different genres of writing and modes of mediation into my academic account. As any other form of representation in anthropological writing, reproducing textual interactions from digital media platforms and including user-generated content in one's ethnographic account present all the classical conundrums highlighted by the 'writing culture' debates (Clifford \& Marcus 1986), as well as a host of ethical questions associated with the notions of privacy, informed consent, copyright and intellectual property. Common questions related to the representation of digital media data include: Can I reproduce a private chat conversation to support an argument in my writing? Should I change pseudonyms and identity markers to protect the participants? Whose permissions should I seek for the publication of an image publicly shared online? How to credit users for their creations while respecting their privacy?

These questions have been recurrently asked and answered in a rich repertoire of discussions regarding the ethics of internet research, which have consistently agreed on the baseline necessity to prioritise what research participants and digital media users give importance to: 'Changing not only real names, but also aliases or pseudonyms (where used) proves the respect of the researchers for the social reality 
of cyberspace' (Paccagnella 1997). Widespread agreement regarding the digital media research ethics includes disclosing one's professional persona when collecting data in online communities, thoroughly anonymising or pseudonymising personal details and identity markers when recognisable or searchable content, seeking consent for the publication of private communications, giving credit for the reproduction of authorial creations (Bruckman 2002), and so on. These discussions move research ethics away from the risk evaluation and informed consent prescriptions of human subject research, towards more relational and situational ethics negotiated according to the digital media context at hand. Following the realisation that ethnographic accounts develop out of the researcher's authorial choices and compositional activities (O’Dell \& Willim 2011, p. 29), Annette Markham provocatively argues that digital ethnographers should embrace the suspicious practice of fabrication in order to overcome conservative and paralysing tendencies in qualitative research:

Traditional methods for protecting privacy by hiding of anonymizing data no longer suffice in situations where social researchers need to design studies, manage data, and build research reports in increasingly public, archivable, searchable, and traceable space. (2012, p. 336)

As prescriptive approaches to internet research ethics are beaten around the thickening bushes of changing digital media platforms, constantly revised terms of consent and complicated personal relationships with privacy and disclosure, fabrication becomes a lean strategy for 'embedding ethics inductively into research practice, by allowing the specific needs of the context to play a stronger role in determining "best practice” procedures' (p. 341).

Markham's argument in favour of fabrication is a sensible one. Even when grounded on extensive datasets, hundreds of fieldnotes and collections of traces, the accounts produced by digital ethnographers end up including an extremely narrow selection of inscriptions, often thoroughly edited, translated, scrambled, rephrased, anonymised, cropped, selectively blurred and collated according to a constellation of ethical, argumentative and aesthetic authorial decisions. In the specific example of a group chat discussion included in my doctoral dissertation, I have ended up choosing one specific hour of conversation from much longer and untranslated logs that I had earmarked in my fieldnotes according to their theme, participants and context. After translating the selected part of transcript, I edited out personal details, elided repetitions and typos, assigned pseudonyms to all discussants, evidenced key terms and included explanatory parentheses, and formatted the conversation so that it could be easily readable in the context of my dissertation while also preserving the flow of a prototypical group chat session on $\mathrm{QQ}$. 


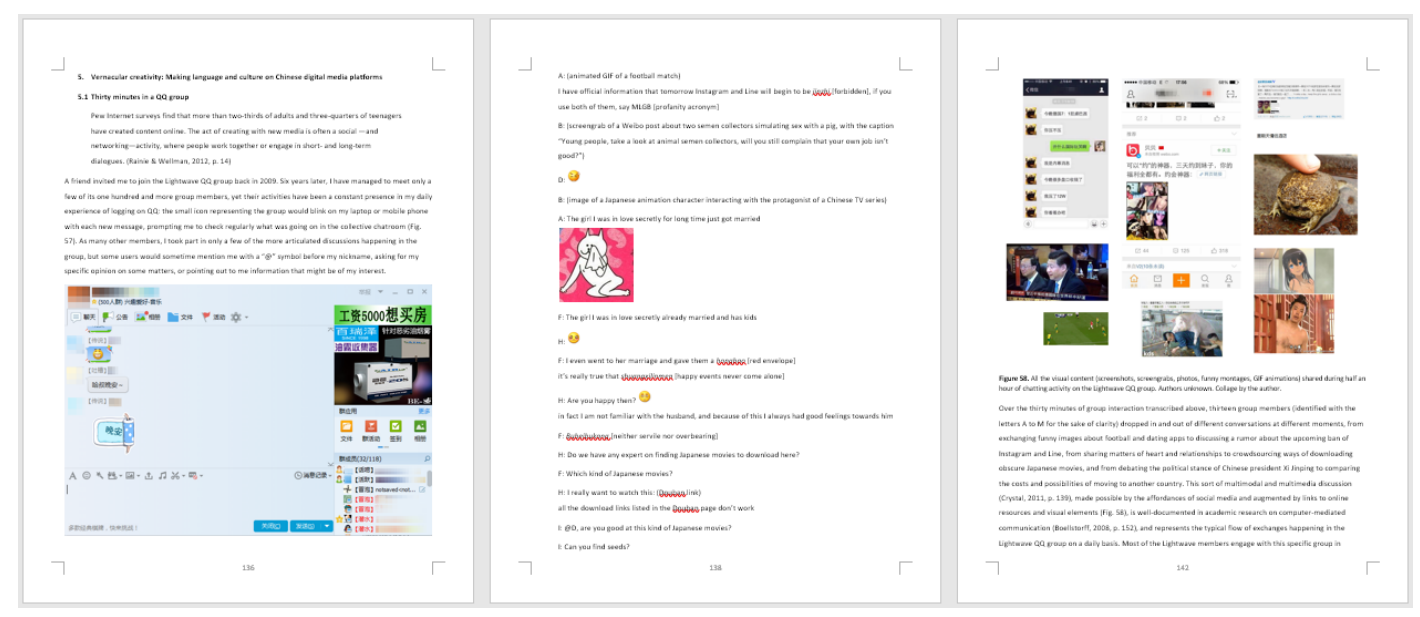

Figure 3. Three pages from my doctoral dissertation, combining a screenshot of the $Q Q$ chat window, a transcript of a group discussion complete with emoticons and stickers, a collage of images shared during an hour of interactions, and my own description of the situation.

In order to complement my account with a visual component, I retrieved the discussion through the software's chat backlogs, downloaded all the images, screenshots and emoticons used during the hour of interactions, back-traced them through a reverse image query on a local search engine, and composed them into a page-sized collage that I could then include in my dissertation as an illustration. Eventually, spanning six pages of my dissertation, this representation of an hourlong group chat is a fabricated account sourced from different kinds of data both captured during fieldwork and retrieved at the time of writing, a carefully crafted composition intended to offer readers an experience of a particular kind of digital media use. As in Markham's methodological proposal, fabrication becomes not just an ethical practice, but 'a way of embracing the agency of the researcher in this process, by first claiming and then actively enacting one's role as editor, translator, and indeed, the fabricator of the story' (2012, p. 345).

Fabrication is thus inextricably linked to the idea of expertise. In claiming and embracing one's role as editor, translator, and fabricator of multimedia and multimodal vignettes, of composites of events, identities and inscriptions, the digital ethnographer implicitly establishes competence and knowledgeability over a certain sociotechnical context. The compositional choices behind an account are justified by an expertise derived from the ethnographer's prolonged experiences and situated learning resulting in the ideal process of 'going native' (Hastrup 1990, p. 46), which supposedly provides us with the necessary sensibilities and competencies to select what is representative, to translate what is relevant, to emphasise what is peculiar, to cut out what is redundant, and to protect what is sensitive - in short, to fabricate an effective and ethical ethnographic account. This process of expertise acquisition is part and parcel of the ethnographic mythology: in my case, both 
research participants and colleagues expressed admiration at my dedication to delve into the linguistic and semiotic repertoires of Chinese digital media - the former by praising my vernacular competence ('You know slang terms even I have never heard about!'), the latter by recognizing the time and effort needed to acquire the necessary sociotechnical literacy ('You must have spent a lot of time learning how to use all those Chinese apps.')

While enjoying the flattering attributions of expertise that come with public engagement about my research topic, I often feel troubled by the way they blur my authorial role into the figure of the social media savvy or the computer geek, hiding how most ethnographic research is actually grounded on a patchy process of discovery, a messy interaction between my puzzled inquiries and the patient explanations of research participants. It is safe to say that most of the 'expertise' included in my research accounts comes from the interpretive and translational efforts of committed online communities I rely upon, and from the kind help of friends who bear with my clueless questions about the latest internet celebrity or slang term. Digital ethnographers are often closer to practical brokers, curious newcomers relying on the knowledgeability and interpretive guidance of what Holmes and Marcus (2008) call 'para-ethnographers', local experts who are already doing our work. Without detracting from the usefulness of fabrication as an ethnically promising representational strategy, it should be remembered how the figure of the expert fabricator becomes an enticing professional illusion that easily overrides the messy, processual and thickly social construction of local expertise. Behind our complex data visualisations, creative multimedia representations and experimental writing lie precarious knowledges pieced together from naively eager participation in coarsely-pruned networks: if, as Markham suggests, 'one way to demonstrate the rigor of the analysis is to build transparency into the account' (2012, p. 348), perhaps the most urgent aspect to make transparent is the pointillist and serendipitous nature of learning hidden behind our expert and ethical fabrications.

\section{TO BE HONEST,}

Starting from the distasteful performance my elevator pitch, I have hinted at how much work spent on the athletics of professionalism and persuasion is dedicated to the performance of disciplinary belonging: deploying half-truths, strategic simplifications and circumstantial lies in order to position ourselves vis-à-vis the disciplinary culture of anthropology. After reviewing the methodological literature of the (broadly intended) disciplinary field of 'digital ethnography' - a research practice often pictured as a fashionable approach that is also problematic, excitingly innovative but also anxiety-inducing - I highlighted how the construction of its epistemic culture happens through claims to distinction, apologetic rhetorics, and strategies of objectification (Beaulieu 2004). 
Riffing on the title of Fine's 1993 article, I have then proposed three lies of digital ethnography, roughly related to the very central issues of fieldwork, participation, and representation. These three lies clearly echo Fine's portrayals of the honest ethnographer (1993, p. 274), the precise ethnographer (p. 278), the observant ethnographer (p. 279), the unobtrusive ethnographer (p. 281) and the literary ethnographer (p. 288), and have evident overlaps with the four strategies of objectification (field, technology, intersubjectivity and capture) identified by Beaulieu (2004). Throughout this article, I put forward three archetypes typifying professional illusions that are part and parcel of doing ethnographic work about, on, with and through digital media. In the first archetype, that of the networked field-weaver, I have identified the lies I told myself and others about the nearomnipotent role I took in cutting sprawling sociotechnical networks down to size into manageable multi-sited fieldsites. The second figure, that of the eager participant-lurker, evidences how the anxieties and apologetics of negotiating and establishing ethnographic presence in networked fields end up obscuring the actual modes of participation embraced by both the researcher and the participants. Through the third character, the expert fabricator, I reflected on the ethical quandaries behind ethnographic accounts increasingly reliant on the incorporation of multiple media and inscriptions, and questioned the expertise assumed by embracing fabrication as a representational strategy.

These three lies of digital ethnography, along with the archetypal figures embodying them as professional illusions, are imagined from reflexive look back at my own research practice - and especially at how I constructed my own ideas of fieldwork, participation and representation during my graduate years. As I warned in the introduction, these three portraits are not meant to unveil the prurient underbelly of an academic discipline nor to accuse other researchers of being blind to their own deceptions, but are rather intended to reflect on which professional illusions are current in our research field, which issues we pressure each other to devise half-truths about, which lies we use to cover the tracks leading to our decisions, and so on. My writing is based on an exercise of self-reflexivity, a heuristic device widely recognised as foundational in qualitative research (Baym 2009, p. 185) to the point of becoming a cliché - at times even condemned as a conceit leaving anthropology as a discipline 'confined to the theatre of its own operations' (Ingold 2014, p. 393). Yet I hope that the arguments I developed will not spin in a selfconceited void, but could rather inspire, challenge and guide the epistemological decisions of fellow researchers.

Ultimately, rather than adding more normative prescriptions about 'how not to lie with ethnography' (Duneier 2011) and demanding the institutionalisation of reliability paradigms (p. 10), the conclusion might be a suggestion to give a shape to one's own lies, and learning to lie productively, lie provocatively, lie constructively, and lie contextually. As repeatedly argued, doing good ethnographic research consists of 'finding practical and defensible balancing points between opposing tensions' (Baym 2009, p. 173), and making accounts that are 'properly 
responsible and accountable to their audiences and their informants' (Hine 2013, p. 6). To be honest about one's methodological lies would then become not just an apologetic confession or a formalised exercise in self-reflexivity, but also an important methodological heuristic to help capturing what would otherwise, as John Law puts it, be 'distorted into clarity' (2004, p. 2). As Fine concludes in his 1993 article, 'These lies are not lies that we can choose, for the most part, not to tell; they are not claims that we can avoid entirely. We must suffer the reality that they are part of the methodology' (1993, p. 290). Weaving networked fields, essentializing one's own participation, and engaging in expert fabrication are part and parcel of doing ethnographic research on, through and about digital media. Rather than hiding these strategic simplifications and pragmatic half-truths behind the professional front of anxiety-inducing elevator pitches, embracing the lies of digital ethnography might help being more honest about them.

\section{NOTES}

1 Gary Alan Fine kindly brought to my attention how Three Lies of Ethnography was written in the disciplinary context of sociology, where ethnography is commonly adopted as a qualitative method for research on the field. The present article has a more anthropological slant, reflecting the degree to which digital ethnography has been primarily developed by media anthropologists. Regardless of its disciplinary positioning, I hope that my contribution can be useful for anyone using ethnography to do research on, with and about digital media.

\section{FUNDING STATEMENT AND ACKNOWLEDGMENTS}

The author did not receive any specific financial support for this work.

\section{REFERENCES}

Amit, V. (Ed.). (2000). Constructing the field: Ethnographic fieldwork in the contemporary world. Routledge.

Baym, N. K. (2009). What constitutes quality in qualitative internet research? In A. N. Markham \& N. K. Baym (Eds.), Internet inquiry: Conversations about method (pp. 173-189). SAGE Publications.

Baym, N. K., \& Markham, A. N. (2009). Introduction: Making smart choices on shifting ground. In A. N. Markham \& N. K. Baym (Eds.), Internet inquiry: Conversations about method (pp. vii-xix). SAGE Publications.

Beaulieu, A. (2004). Mediating ethnography: Objectivity and the making of ethnographies of the internet. Social Epistemology, 18(2-3), 139-163. https://doi.org/10.1080/0269172042000249264 
Beaulieu, A. (2010). From co-location to co-presence: Shifts in the use of ethnography for the study of knowledge. Social Studies of Science, 40(3), 453470. https://doi.org/10.1177/0306312709359219

boyd, danah. (2008). Why youth $\bigcirc$ social network sites: The role of networked publics in teenage social life. In D. Buckingham (Ed.), Youth, identity, and digital media (pp. 119-142). MIT Press.

Bruckman, A. (2002). Studying the amateur artist: A perspective on disguising data collected in human subjects research on the Internet. Etbics and Information Technology, 4(3), 217-231. https://doi.org/10.1023/A:1021316409277

Burgess, J. (2006). Hearing ordinary voices: Cultural studies, vernacular creativity and digital storytelling. Continuum: Journal of Media E Cultural Studies, 20(2), 201-214. https://doi.org/10.1080/10304310600641737

Burrell, J. (2009). The field site as a network: A strategy for locating ethnographic research. Field Methods, 21(2), 181-199. https://doi.org/10.1177/1525822X08329699

Clifford, J., \& Marcus, G. E. (Eds.). (1986). Writing culture: The poetics and politics of ethnography. University of California Press.

Correll, S. (1995). The ethnography of an electronic bar: The Lesbian Cafe. Journal of Contemporary Ethnography, 24(3), 270-298. https://doi.org/10.1177/089124195024003002

de Seta, G. (2015). Dajiangyou: Media practices of vernacular creativity in postdigital China [PhD Thesis]. The Hong Kong Polytechnic University.

Dicks, B., Soyinka, B., \& Coffey, A. (2006). Multimodal ethnography. Qualitative Research, 6(1), 77-96. https://doi.org/10.1177/1468794106058876

Duneier, M. (2011). How not to lie with ethnography. Sociological Methodology, 41(1), 1-11. https://doi.org/10.1111/j.1467-9531.2011.01249.x

Farnsworth, J., \& Austrin, T. (2010). The ethnography of new media worlds? Following the case of global poker. New Media E Society, 12(7), 1120-1136. https://doi.org/10.1177/1461444809355648

Fine, G. A. (1993). Ten lies of ethnography: Moral dilemmas of field research. Journal of Contemporary Ethnography, 22(3), 267-294. https://doi.org/10.1177/089124193022003001

Fine, G. A., \& Shulman, D. (2009). Lies from the field: Ethical issues in organizational ethnography. In S. Ybema, D. Yanow, H. Wels, \& F. Kamsteeg (Eds.), Organizational ethnography: Studying the complexities of everyday life (pp. 177-195). SAGE Publications.

Geiger, R. S., \& Ribes, D. (2011). Trace ethnography: Following coordination through documentary practices. 2014 47th Hawaii International Conference on System Sciences, 1-10. https://doi.org/10.1109/HICSS.2011.455 
Hannerz, U. (2003). Being there. . . And there. . And there! Reflections on multi-site ethnography. Ethnography, 4(2), 201-216.

https://doi.org/10.1177/14661381030042003

Hastrup, K. (1990). The ethnographic present: A reinvention. Cultural Anthropology, 5(1), 45-61. https://doi.org/10.1525/can.1990.5.1.02a00030

Hine, C. (2000). Virtual ethnography. SAGE Publications.

Hine, C. (2005). Research sites and strategies: Introduction. In C. Hine (Ed.), Virtual methods: Issues in social research on the Internet (pp. 109-112). Berg.

Hine, C. (2007). Connective ethnography for the exploration of e-science. Journal of Computer-Mediated Communication, 12(2), 618-634. https://doi.org/10.1111/j.1083-6101.2007.00341.x

Hine, C. (2013). The Internet. Oxford University Press.

Holmes, D. R., \& Marcus, G. E. (2008). Para-ethnography. In L. M. Given (Ed.), The SAGE encyclopedia of qualitative research methods (pp. 595-597). Sage Publications.

Howard, P. N. (2002). Network ethnography and the hypermedia organization: New media, new organizations, new methods. New Media E Society, 4(4), 550-574. https://doi.org/10.1177/146144402321466813

Ingold, T. (2014). That's enough about ethnography! HAU: Journal of Ethnographic Theory, 4(1), 383-395. https://doi.org/10.14318/hau4.1.021

Ito, M. (1996). Theory, method, and design in anthropologies of the Internet. Social Science Computer Review, 14(1), 24-26.

Jenkins, H., Ford, S., \& Green, J. (2013). Spreadable media: Creating value and meaning in a networked culture. New York University Press.

Law, J. (2004). After method: Mess in social science research. Routledge.

Leander, K. M., \& McKim, K. K. (2003). Tracing the everyday 'sitings' of adolescents on the Internet: A strategic adaptation of ethnography across online and offline spaces. Education, Communication E Information, 3(2), 211-240. https://doi.org/10.1080/1463631032000092037

Levy, K. E. C. (2015). The user as network. First Monday, 20(11). https://doi.org/10.5210/fm.v20i11.6281

Marcus, G. E. (1995). Ethnography in/of the world system: The emergence of multi-sited ethnography. Annual Review of Anthropology, 24, 95-117.

Markham, A. N. (2012). Fabrication as ethical practice: Qualitative inquiry in ambiguous Internet contexts. Information, Communication E Society, 15(3), 334-353. https://doi.org/10.1080/1369118X.2011.641993

Moser, S. (2007). On disciplinary culture: Archaeology as fieldwork and its gendered associations. Journal of Archaeological Method and Theory, 14(3), 235-263. https://doi.org/10.1007/s10816-007-9033-5

Nardi, B. A. (1996). Cyberspace, anthropological theory, and the training of anthropologists. Social Science Computer Review, 14(1), 34-35.

O'Dell, T., \& Willim, R. (2011). Composing ethnography. Ethnologia Europaea: Journal of European Ethnology, 41(1), 27-39. 
Orgad, S. (2005). From online to offline and back: Moving from online to offline relationships with research informants. In C. Hine (Ed.), Virtual methods: Issues in social research on the Internet (pp. 51-65). Berg.

Paccagnella, L. (1997). Getting the seats of your pants dirty: Strategies for ethnographic research on virtual communities. Journal of Computer-Mediated Communication, 3(1). https://doi.org/10.1111/j.1083-6101.1997.tb00065.x

Pink, S., Horst, H., Postill, J., Hjorth, L., Lewis, T., \& Tacchi, J. (2016). Digital ethnography: Principles and practice. SAGE Publications.

Postill, J. (2017). Remote ethnography: Studying culture from afar. In L. Hjorth, H. Horst, A. Galloway, \& G. Bell (Eds.), The Routledge companion to digital ethnography (pp. 61-69). Routledge.

Rogers, R. (2013). Digital methods. MIT Press.

Strathern, M. (1996). Cutting the network. The Journal of the Royal Anthropological Institute, 2(3), 517-535. https://doi.org/10.2307/3034901

Wittel, A. (2000). Ethnography on the move: From field to net to Internet.

Forum Qualitative Sozialforschung / Forum: Qualitative Social Research, 1(1). http://www.qualitative-research.net/index.php/fqs/article/viewArticle/1131 